\title{
Personel İş Zekası Sistemi ve Veri Madenciliği ile Personel Memnuniyetinin Ölçülmesi
}

\author{
Gizem Çetin ${ }^{1 *}$, Ömer Özgür Tanrı̈ver ${ }^{2}$ \\ ${ }^{1}$ Ankara Üniversitesi, Mühendislik Fakültesi, Bilgisayar Mühendisliği Bölümü, Ankara, Türkiye (ORCID: 0000-0003-0486-8758) \\ 2 Ankara Üniversitesi, Mühendislik Fakültesi, Bilgisayar Mühendisliği Bölümü, Ankara, Türkiye (ORCID: 0000-0003-0833-3494)
}

(International Symposium on Multidisciplinary Studies and Innovative Technologies (ISMSIT) 2020 - 22-24 Ekim 2020)

(DOI: 10.31590 /ejosat.823340)

ATIF/REFERENCE: Çetin, G., \& Tanrı̈̈ver, Ö. Ö. (2020). Personel İş Zekası Sistemi ve Kümeleme Analizi Yöntemi ile Personel Memnuniyetinin Ölçülmesi. Avrupa Bilim ve Teknoloji Dergisi, (Özel Sayı), 323-334.

$\ddot{\mathbf{O} z}$

Veri madenciliği uygulamaları ve iş zekası sistemleri verileri anlamlandırarak bilgiye dönüştürülmesinde ve kuruluşlara karar verme süreçlerinde yardımcı olmak için kullanılır. Çalışmada bir devlet kurumunun personel verileri üzerinde iş zekası ve veri madenciliği süreçleri gerçekleştirilerek verilerin yönetimini sağlamak ve dinamik analizler ile stratejik öngörülerin yapılabilmesi amaçlanmıştır. İş zekası süreçlerinin uygulanmasında Microsoft iş zekası araçlarından SSIS (SQL Server Integration Service), SSAS (SQL Server Analysis Service) ve Power BI kullanılmıştır. Öncelikle veri yapısı modellendirilmiş̧ olup ETL (Extract-Transform-Load) sürecinden geçirilerek anlamlı hale getirilen veri, veri ambarına SSIS programı ile aktarılmıştır. Daha sonra SSAS programı ile OLAP veri küpü oluşturulmuştur. Son olarak da OLAP küpü veri kaynağı olarak belirlenip zengin görsel araçlara sahip olan ve veri analizini çok daha etkili hale getiren Power BI iş zekası aracı kullanılarak çeşitli görsellerle veri analizi gerçekleştirilmiştir. Böylece, karar vericilerin veri analizini etkin bir şekilde yapabilecekleri bir karar destek sistemi geliştirilmiştir. Çalışmada kümeleme analizi yöntemlerinden biri olan K-Means algoritması ve birliktelik kurallarından kurallarından Apriori algoritması ile bir devlet kurumundaki İç Kontrol Sistemi anketi verileri kullanılarak personel memnuniyet analizi yapılmıştır. Veri madenciliği aracı olarak ise içerisinde bulundurduğu bir çok algoritma sayesinde verilerden bilgi çıkarımı yapılabilmesine olanak sağlayan ve açık kaynak kodlu bir araç olması sebebi ile WEKA kullanılmıştır. Kümeleme analizi sonucunda oluşan farklı personel grupları detaylı incelenerek bu gruplara nasıl yaklaşılması gerektiği ve nasıl hitap edilmesi gerektiği belirlenmiş̧ir. Her grubun memnuniyet durumunun farklılaşan noktaları belirlenerek, stratejiler ve uygulama faaliyetleri bu grubun ihtiyacına göre planlanmıştır. Apriori algoritması, personelin İç Kontrol Sistemi anket sorularına vermiş olduğu cevaplar arasında anlamlı ilişkileri bulmak, bu ilişkilerden faydalanarak personelin çalıştığı birimden memnuniyetini karşılaştırarak anlamlı sonuçlar elde etmek ve çalışılan birimden memnun olmama nedenlerini keşfetmek için kullanılmıştır. Böylece İç Kontrol Sistemi anketi verilerinden anlamlı ve yararlı bilgiler elde etmek ve bu bilgiler ışığında personel karar destek planlama faaliyetlerinde destek olmak amaçlanmıştır.

Anahtar Kelimeler: Veri Madenciliği, Kümeleme, Birliktelik Kuralları, Personel Memnuniyeti, Karar Destek Sistemleri.

\section{A Personnel Business Intelligence System and Measuring Personnel Satisfaction with Data Mining}

\begin{abstract}
Data mining applications and business intelligence systems are used to make sense of data and to help organizations in their decisionmaking processes. In the study, it is aimed to manage the data by performing business intelligence and data mining processes on the personnel data of a government institution and to make strategic predictions with dynamic analysis. Microsoft business intelligence tools SSIS (SQL Server Integration Service), SSAS (SQL Server Analysis Service) and Power BI have been used in the implementation of business intelligence processes. First of all, the data structure was modeled and the data, which was made meaningful by passing the ETL (Extract-Transform-Load) process, was transferred to the data warehouse with SSIS program. Then, OLAP data cube was created with SSAS program. Finally, data analysis was carried out with various visuals using the Power BI business intelligence tool, which
\end{abstract}

\footnotetext{
* Sorumlu Yazar: Ankara Üniversitesi, Mühendislik Fakültesi, Bilgisayar Mühendisliği Bölümü, Ankara, Türkiye, ORCID: 0000-0003-0486-8758, gizemcetin06@gmail.com
} 
has been identified as the OLAP cube as a data source and has rich visual tools and makes data analysis much more effective. Thus, a decision support system has been developed where decision makers can perform data analysis effectively. In the study, personnel satisfaction analysis was performed using the K-Means algorithm, one of the cluster analysis methods, and the Apriori algorithm, one of the association rules, and the Internal Control System survey data in a government institution. As a data mining tool, WEKA is used because it is an open source tool that allows information extraction from data thanks to many algorithms it contains. The different staff groups formed as a result of the cluster analysis were examined in detail, and how these groups should be approached and addressed was determined. Different points of satisfaction status of each group were determined and strategies and implementation activities were planned according to the needs of this group. The Apriori algorithm has been used to find meaningful relationships between the responses of the personnel to the Internal Control System survey questions, to obtain meaningful results by comparing the satisfaction of the personnel from the unit they work in, and to discover the reasons for their dissatisfaction with the unit they work with. So it is aimed to obtain meaningful and useful information from the internal control system survey data and to support personnel decision support planning activities in the light of this information.

Keywords: Machine Learning, Clustering, Association Rules, Personnel Satisfiction, Decision Support Systems.

\section{Giriş}

İş zekası, kurumların karar verme ve yönetim kabiliyetlerinin artırılmasına yardımcı olan; çok sayıda verinin kurumsal bilgiye dönüştürülmesini ve böylelikle kurumların rekabet ortamında avantaj sağlamasına yönelik kavramlar, metotlar, süreçler ve yazılımlar bütünü olarak tanımlanabilir. (Michael, 1999). Günümüz dünyasında yüksek bir ivmeyle artan bilgi hacmiyle beraber yöneticiler etkin kararlar alma adına iş zekâsı sistemlerinden faydalanabilmektedirler (Lin ve ark., 2009). İş zekâsı sistemlerinin en önemli faydalarından biri karar vermede sağladığı avantajlardır (Negash, 2004; Watson ve ark., 2002).

Bir kuruluşun, bilinçli kararlar alabilmesi için sahip olduğu verileri en iyi şekilde kullanıp onları anlamlandırması gerekmektedir. $\mathrm{Bu}$ sebepten dolayı iş zekası ve veri madenciliği çözümlerine artan bir ihtiyaç vardır. Bu çalışmada bir devlet kurumunun personel verileri üzerinde iş zekası ve veri madenciliği süreçleri gerçekleştirilmiş ve örnek uygulama yapılmıştır. Personel verilerinin yönetilmesi, personel işe alım stratejisinin planlamasına katkı sağlanması ve kullanıcıların dinamik bir şekilde analiz yapabilmeleri için bir karar destek sistemi oluşturulması amaçlanmıştır. Kurumun Personel Bilgi Sisteminde geleneksel raporlama araçları ile statik bir şekilde oluşturulan raporlar mevcuttur. Kullanıcılar veriler ile dinamik analiz yapamamaktadır. Alınabilecek rapor sayısı ve türü kısıtlıdır. Bu nedenden dolayı iş zekası çözümleri ile kullanıcıların dinamik bir şekilde analiz yapabileceği bir iş zekası sistemi oluşturmak amaçlanmıştır.

Veri madenciliği, sistemde daha önceden bulunan ama bilinmeyen ilgi çekici, sıra dışı ve yararlı olabilecek verinin anlamlı bilgiye dönüştürülme sürecidir (Shen, 2007). Bu çalışmada birliktelik kuralları ve kümeleme analizi incelenmiştir. Bir devlet kurumunda yapılan İç Konrol Sistemi anketinde yer alan sorulara personel tarafından verilen cevaplar veri madenciliği yöntemlerinden Apriori birliktelik kuralları ve K-Means kümeleme analizi kullanılarak irdelenmiştir ve sonuçlar değerlendirilerek memnuniyet analizi yapılmıştır.

Bu konu ile ilgili yapılan çalışmalar incelendiğinde; Jung ve Suh’in 2019 yılında yaptığı çalışmada çevrimiçi çalışan görüşleri ile personelin iş tatmini faktörleri ortaya konulmuştur. Bu çalışmada ilk olarak, Latent Dirichlet Tahsisatı ${ }^{2}$ (LDA) kullanarak Güney Kore'deki çalışanların en büyük çevrimiçi şirket değerlendirme sitesi olan jobplanet.co.kr'de yayınlanan 35.063 çalışan görüşünden iş memnuniyeti faktörleri belirlenmiştir. Ardından, faktör bazında analizler yapılıp sektör, şirket, grup ve kronolojik seviyelerde her bir iş memnuniyeti faktörünün duyarlılığı ve önemi ölçülmüştür. Bu çalışmadan elde edilen sonuçlar, işletme yöneticilerine, çalışanlarının çeşitli yönlerden iş memnuniyetini yönetmeye ilişkin kararlar alma konusunda derin içgörüler sağlamıştır. Ayrıca iş tatmini faktörleri hakkında kapsamlı bir bakış açısı sağlayarak, işletme yöneticilerinin karar vermesini desteklemek için yeni bir yaklaşım önermektedir. Son olarak, literatürde dikkate alınmayan beş yeni iş tatmini faktörü bulunmuştur. Bunlar proje, yazılım geliştirme, firmalar arası ilişki, pazarlama ve yurtdışı iş imkanıdır. Bu çalışmanın yapılan çalışmadan farkı kullanılan çalışan görüşü veri mikarı çok daha fazla olmasıdır (Jung ve Suh, 2019).

Sheybani tarafından 2019 yılında yapılan çalışmada Amerika Birleşik Devletleri'ndeki iş memnuniyetini ve iş tatminizliğini etkileyen faktörleri değerlendirmeyi amaçlanmıştır. İş tatmini ile ilgili ve Amerika Birleşik Devletleri Ulusal Fikir Araştırma Merkezi tarafından toplanan 9 farklı eyalette 891 erkek ve 1153 kadına ait toplam 2044 kayıt içeren veriler bu çalışmada kullanılmıştır. Çalışanların iş tatmininin örüntülerini bulmak için Clementine 12.0 veri madenciliği yazılımı kullanılarak veri kalıpları keşfedilmiş ve CHAID karar ağacı veri madenciliği yöntemi ile iş memnuniyetini etkileyen faktörler belirlenmiştir. Sonuçlara göre insanların küçük bir yüzdesinin işlerinden memnun olmadığı ortaya çıkmıştır. Bireylerin işverenleri için çalışmaktan gurur duymamaları ve stresli çalışma ortamının iş tatminsizliği üzerinde büyük bir etkisi olabileceği sonucuna varılmıştır. Ayrıca, organizasyon yönetimi ile çalışanlar

\footnotetext{
${ }^{2}$ Bir metin belgesinde "topics(konular)" adı verilen kelime gruplarını bulmak için kullanılan denetimsiz(unsupervised) bir yaklaşımdır.
} 
arasında iyi bir ilişki olmamasının iş tatminsizliğine yol açabileceği sonucuna varılmıştır. Sheybani tarafından yapılan çalışmanın bu çalışmadan farkı sınıflandırma yöntemlerinden karar ağacı algoritması kullanılmasıdır (Sheybani, 2019).

Gupta ve arkadaşlarının yaptıkları çalışmada Twitter'da maaşlarından dolayı iş doyumu yüksek olanların ve daha az maaşla çalışanların beyanlarına göre tweet'leri incelenerek analizler ortaya konulmuştur. Toplam 142.656 tweet verilerine veri madenciliği teknikleri uygulanmıştır. Uygulanan algoritmalar arasında en yüksek başarı oranı Grandient Boosted Tree'ye aittir ve veri kümesi üzerinde \% 99'un üzerinde bir başarı ile doğru bir şekilde sınıflandırabilmiştir. Uygulanan makine öğrenmesi algoritmaları sonucunda, aldıkları maaştan memnun ve memnun olmayanların cümle yapıları, kullanılan kelimeler ve yaptıkları gönderiler arasında anlamlı bir fark olduğu görülmüştür. Bu çalışmada makine öğrenimi sayesinde iş tatmini yüksek olan ve iş tatmini yüksek olmayan kişiler, twitter hesapları analiz edilerek öğrenilebilir sonucuna varılmıştır. Gupta tarafından yapılan çalışmanın bu çalışmadan farkı veri madenciliği tekniklerinden sınıflandırma yöntemlerinin kullanılması ve twitter verilerinin kullanılmasıdır (Gupta ve ark., 2020).

Al-Radaideh ve Nagi tarafından yapılan çalışmada, çalışanların performansını tahmin etmek için veri madenciliği teknikleri kullanılarak bir sınıflandırma modeli oluşturulmuştur. Sınıflandırma modeli oluşturulurken karar ağacı algoritması kullanılmıştır. Oluşturulan modeli doğrulamak için, birkaç şirketten toplanan gerçek veriler kullanılarak birkaç deney yapılmıştır. İş unvanı ve ardırdan üniversite türü performansı etkileyen en önemli özellik olarak bulunmuştur. Çalışmaya göre şirket yöneticileri ve insan kaynakları departmanları için bu model, yeni başvuran personel performansının tahmin edilmesinde kullanılabilir. Bu durumda, kötü performans gösteren çalışanın işe alınmasıyla ilgili herhangi bir riski önlemek için çeşitli önlemler alınabilir. Al-Radaideh ve Nagi tarafından yapılan çalışmada çalışanların performansı sınıflandırma yöntemleri ile değerlendirilmiştir (Al-Radaideh ve Al Nagi, 2012).

Eren'in 2018'de yaptı̆̆g doktora tezi çalışmasında iş zekâsı sistemlerinin temel faydalarından birisi olan karar verme aktivitesinin ne olduğu, günümüzde karar verme teknolojileri ve iş zekâsı sistemlerinin karar vermedeki etkinliği açıklanmıştır. Karar vermede teknolojinin rolü açıklanarak iş zekâsı sistemlerinin bu alandaki üstünlüğü belirtilmiştir. İş zekâsı sistemlerinin ne tür faydalar sağladığı ve bu faydaların nasıl ölçülebileceğine dair bilgiler sunularak çalışmaya yön verilmiştir. Ayrıca bu tezde iş zekâsı sistemlerinin karar verme ve performans üzerine etkileri araştırılmış olup karar verme ve performansı etkileyen yapılar belirlenmiş ve bu yapıların birbirleri üzerindeki etkileri ortaya konulmuştur. Eren tarafından yapılan bu çalışmada iş zekası sistemlerinin karar verme üzerindeki etkileri detaylı bir şekilde incelenmiştir. Yapılan bu çalışmada ise personel verilerinin iş zekası uygulamasına ek olarak veri madenciliği ile karar verme etkinliği incelenmişitir (Eren, 2018).

Talukdar'ın tarafından yapılan çalışmada ise insan kaynakları sorunlarının sistematik ve etkili bir şekilde ele alınması için iş zekası sistemlerinin kullanılmasını amaçlamaktadır. Ayrıca, bu çalışma SAP, SAS, Oracle ve IBM Cognos Business Intelligence gibi iş zekasının çeşitli modelleri aracılığıyla İnsan Kaynakları Yönetimi (HRM) alanında iş zekasının önemi belirtilmektedir. Çalışma, iş zekasının bir parçası olarak İK analitiğinin, bir organizasyonun İnsan Kaynakları Yönetimi veri yönetimi ve depolama teknolojilerini kullanarak İnsan Kaynaklarını sistematik olarak yönetmesine yardımcı olduğu sonucuna varmaktadır (Talukdar, 2016).

Chien ve Chen tarafından 2008 yılında yapılan çalışmada personel seçimi için yararlı kurallar oluşturmak amacıyla karar ağacına ve ilişkilendirme kurallarına dayalı bir veri madenciliği çerçevesi geliştirerek kuruluşların kendilerine en uygun yetenekleri bulmak için etkili personel seçme mekanizması geliştirilmesi amaçlanmıştır. Yeni başvuranların özgeçmişleri, iş başvuruları ve görüşmelerinden seçilen özelliklere bağlı olarak performansını tahmin etmek için veri madenciliği tekniklerini kullanarak bir model oluşturulup çalışan seçiminin iyileştirilmesi üzerinde çalışmışlardır. Yapılan çalışmanın sonuçları bu yaklaşımın pratik uygulanabilirliğini göstermiştir. Ayrıca, sonuçlardan spesifik işe alım ve insan kaynakları yönetimi stratejileri oluşturulmuştur. Al-Radaideh ve Nagi tarafindan yapılan çalışmadaki gibi çalışan performansı karar ağaçları ile tahmin edilmeye çalışılmıştır. Ayrıca yeni iş başvurularında personel seçme mekanizması geliştirilmiştir (Chien ve Chen, 2008).

Yadav ve arkadaşları tarafından yapılan çalışmada çalışanın davranışlarını ve niteliklerini sınıflandırma tekniklerini kullanılarak analiz edilmiştir ve çalışan kaybını tahmin etmek için bir çerçeve oluşturmuşlardır. Çalışanların işten ayrılması, bir kuruluşu hem zaman hem de maliyet açısından etkileyebilir. Tahmine dayalı geliştirilen model, yalnızca önleyici tedbirlerin alınmasına değil, aynı zamanda işe alma kararlarının alınmasına da yardımcı olmuştur. Bu çalışmanın yapılan diğer çalışmalardan farkı, çalışanın geçmiş verilerindeki eğilimleri kullanılarak çalışanın yakın gelecekte kurumdan ayrılıp ayrılmayacağını Logistic Regression, SVM, Random Forest, Decision Tree and AdaBoost gibi farklı sınıflandırma yöntemleri ile tahmin etmeye yardımcı olmasıdır (Yadav ve ark., 2018).

Genel olarak araştırılan makalelerde çalışanların performansını etkileyen ana özellikler incelenmiştir. Ayrıca incelenen çalışmalarda genel olarak sınıflandırma yöntemleri kullanılmıştır. Bu yapılan çalışmanın ise diğer yapılan çalışmalardan farkı çalışma memnuniyetsizliği sebepleri incelenmesidir. Diğer çalışmalardan bir diğer farkı ise çalışılan birimden memnun olmama nedenlerini keşfetmek için birliktelik kurallarından Apriori algoritması, personelin memnuniyet durumuna göre farklı gruplara ayrılarak, bu gruplara nasıl yaklaşılması gerektiği belirlenmesi için kümeleme yöntemlerinden K-Means algoritması kullanılmasıdır. Ayrıca bu çalışmada veri madenciliği uygulaması ile birlikte iş zekası çözümleri ile yöneticilerin daha hızlı ve doğru karar verebilmelerine yardımcı olmak için personel karar destek sistemi oluşturulmuştur.

Çalışmanın ikinci bölümünde bir devlet kurumuna ait personel verileri ile karar destek uygulaması geliştirilirken yapılan işlemler ve adımlar anlatılmıştır. Personel veri ambarı modellemesinden ve OLAP küpü oluşturma sürecinden bahsedilmiştir. Bu bölümde son olarak da OLAP küpü kullanılarak Power BI iş zekası aracı yardımıyla çeşitli görsellerle veri analizi gerçekleştirilme süreci anlatılıp oluşturulan bir rapordan örnek verilmiştir. Üçüncü bölümde İç Kontrol Sistemi anketindeki sorulara, personelin vermiş olduğu cevaplar 
veri madenciliği yöntemlerinden K-Means kümeleme analizi ve Apriori birliktelik kuralları aracılı̆̆ı ile analiz edilip algoritmaların uygulama adımları, sonuçları açıklanmıştır.

\section{Materyal ve Metot}

\subsection{Personel İş̧ Zekası Sistemi Oluşturulması}

Bu bölümde bir devlet kurumunun personel verileri üzerinde gerçekleştirilen iş zekası süreçleri açıklanmışıtır. Bu çalışmada iş zekası aracı olarak Microsoft SQL Server, Microsoft Visual Studio, SQL Server Data Tool ve Power BI kullanılmıştır. Veri ambarı tasarımı için ise Microsoft SQL Server kullanılmıştır.

Personel verileri nüfus, öğrenim, aile, adres, yabancı dil, eğitim, hizmet, izin, terfi, atama hareketleri, kadro işlemleri, görevlendirme, disiplin ve dava gibi bilgiler içermektedir. Yaklaşık dört bin personele ait bilgiler mevcuttur.

Personel verilerinin Oracle veri tabanından veri ambarına aktarma işlemleri için Microsoft SSIS aracı kullanılmıştır. Veritabanında tutulan veriler ETL işlemleri gerçekleştirildikten sonra ilgili tablolara veri aktarımını sağlamak için .dtsx uzantılı SSIS paketleri oluşturulmuştur. Veri ambarı tasarlanırken Fact ve Dimension tabloları ETL yardımı ile oluşturulmuştur. Tablo 1.'de veri ambarında bulunan bazı fact ve dimension tablolarının açıklamaları ve diğer tablolarla ilişkili olduğu ölçüt alanı verilmiş̧tir. Veri ambarı modellemesi takımyıldızı şemasına göre yapılmıştır. SSIS'te olgu ve boyut tabloları için oluşturulan paketlerin otomatik hergün çalıştırılarak güncel verileri veri ambarına atması için SQL Server’da script hazırlanmışıtır.

Tablo 1. Veri Ambarında bululan bazı fact ve dimension tablolarl

\begin{tabular}{|c|c|c|}
\hline $\begin{array}{l}\text { Fact ve Dimension } \\
\text { Tabloları }\end{array}$ & Açıklama & Ölçüt Alanı \\
\hline FactPerSicil & $\begin{array}{l}\text { Personele ait temel bilgileri (sicil, ad, soyad, cinsiyet, tc kimlik no, kadro no, vs.) } \\
\text { içeren olgu tablosudur. }\end{array}$ & Sicil No \\
\hline FactPerKadro & $\begin{array}{l}\text { Kadrolu personelin kadro bilgisini (birim, unvan, kadro no vs.) içeren olgu } \\
\text { tablosudur. }\end{array}$ & Kadro No \\
\hline FactIsciKadro & $\begin{array}{l}\text { İşçi personele ait kadro bilgisini (birim, unvan, kadro no vs.) içeren olgu tablosudur. } \\
\text { Bu tablosu için belirleyici ölçüt Kadro No alanıdır. }\end{array}$ & Kadro No \\
\hline FactGeciciGorev & $\begin{array}{l}\text { Personelin (işçi, memur) geçici görev bilgisini (süreli ve süresiz geçici görev,vekalet } \\
\text { vs.) içeren olgu tablosudur. }\end{array}$ & Kayit Id \\
\hline FactNufus & $\begin{array}{l}\text { Personelin nüfus bilgisini (doğum yeri, tarihi, medeni durum vs.) içeren olgu } \\
\text { tablosudur. }\end{array}$ & Kayit No \\
\hline DimPersonelTuru & $\begin{array}{l}\text { Personel türü bilgisini (kadrolu personel, sürekli işçi, 4B sözleşmeli vs.) gösteren } \\
\text { tanım tablosudur. }\end{array}$ & Kodu \\
\hline DimPersonelGrup & $\begin{array}{l}\text { Personel alım türü bilgisini (normal, engelli, terör, shçek vs.) gösteren tanım } \\
\text { tablosudur. }\end{array}$ & Kodu \\
\hline DimPerBirim & Kurum teşkilat yapısında bulunan birimlerin bilgisini gösteren tanım tablosudur. & Kodu \\
\hline DimAyrilisNeden & Ayrılan personelin ayrılma nedenini (istifa, emeklilik vs.) gösteren tanım tablosudur. & Kodu \\
\hline DimKurumGirisTarihi & $\begin{array}{l}\text { Personelin kurumda çalışmaya başladığı tarih aralı̆̆ı bilgisinin detaylarını (yıl, } \\
\text { çeyrek, ay, gün vs.) içeren tanım tablosudur. }\end{array}$ & Kodu \\
\hline
\end{tabular}

\subsubsection{OLAP Küpü Tasarımı ve Raporlama}

OLAP yapısı, veriyi çok boyutlu halde tutan ve gerektiği zaman belirli parametreler ile kullanışlı bilgi sağlayan bir sistem olarak tanımlanabilir (Matei, 2010). OLAP; verilerin OLTP yapısındaki gibi iki boyutlu (satır ve sütun) olarak tutulması yerine çok boyutlu küpler halinde tutulduğu ve veriler üzerinde istatistiksel analizlerin yapıladığı veri tabanlarıdır. Sorgu süresini azaltmak için OLAP sunucusundaki veriler, ilişkisel veri modelinde olduğu gibi tablolar (satırlar ve sütunlar) yerine veri küpleri şeklinde düzenlenir (Wang ve ark., 2005). Küpler, satır ve sütun içeren tablolar kullanmak yerine, boyutlardan ve hesaplamalardan (veya ölçümlerden) oluşur (Langit ve ark., 2009).

Bu çalışmada SQL Server Analysis Service Tabular Model kullanılmıştır. Personel verilerinin incelenip analiz yapılabilmesi için OLAP Personel küpü tasarlanmıştır. Küp oluşturmak için veri ambarından Fact ve Dimension tabloları SSAS aracı yardımıyla küpe aktarılmıştır. Şekil 1.'de oluşturulan OLAP küpünden bir kesit verilmiştir. OLAP küpünde measure alanlarının olduğu Fact tabloları, PerSicil, PerKadro, IsciKadro, Nufus, GeciciGorev'dir. Dimension tabloları ise Personel Türü, Personel Grubu, Birim, Ayrılma Nedeni ve Tarihi, Cinsiyet gibi tablolardır. Bu tabloların açıklaması yukarıdaki Tablo 1.'de verilmiştir. Tablolar birbirleri ile Tablo 1.'de verilen ölçüt alanı ile 1-n ilişki kurarak aşağıda verilen şekildeki gibi model oluşturulmuştur. Fact tablolarında DAX (Veri Analizi İfadeleri) formülleri yardımıyla measure değerleri oluşturulmuştur. Örneğin Şekil 1.'de gösterilen PerSicil fact tablosunda "ToplamKayıt", "Aktif Çalışan Personel Sayısı”, “Ayrılan Personel Sayısı” gibi measure alanları vardır. 
Şekil 1. Personel OLAP Küpü yapısl

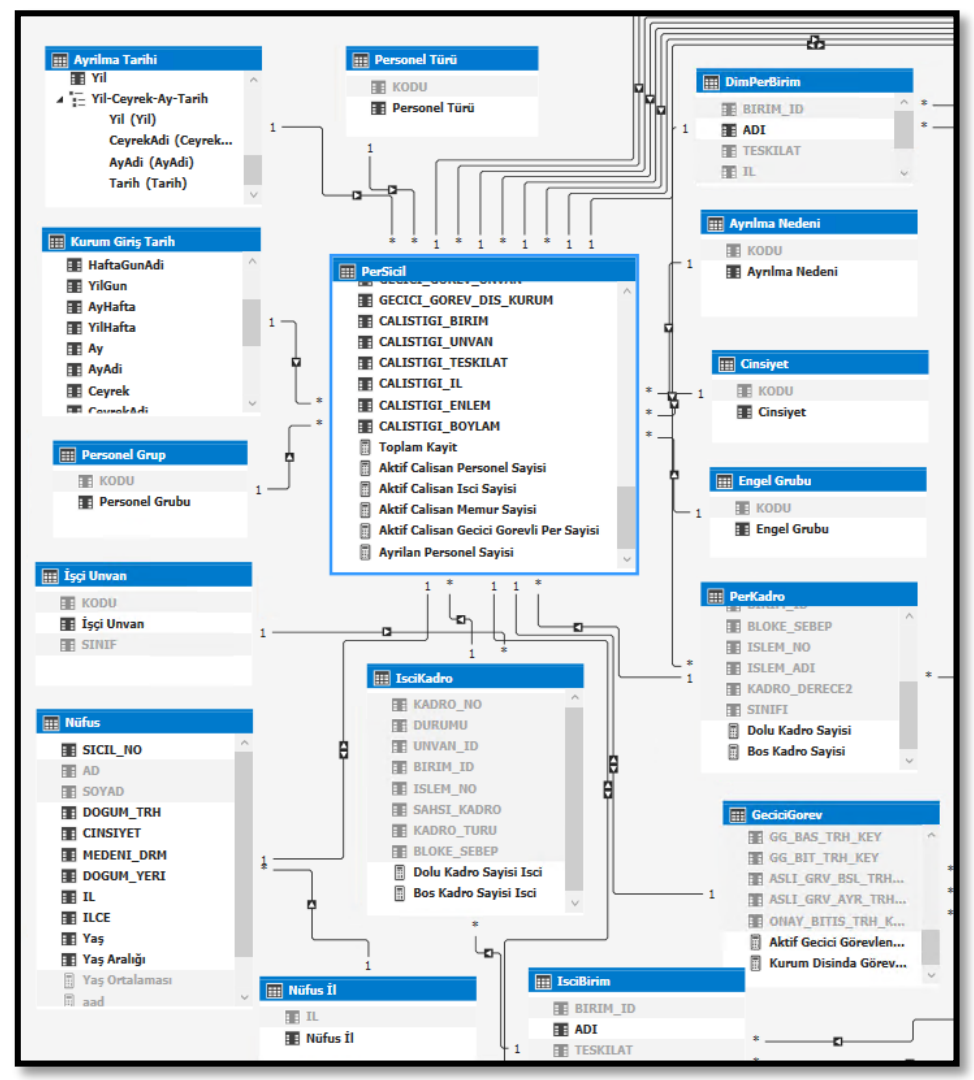

Şekil 2'de OLAP küpü veri kaynağı olarak seçilip Power BI ile hazırlanan raporda Türkiye haritasında personel yaş ortalamasının illere göre dağılımı gösterilmektedir. Haritada istenilen bir il üzerine gelindiğinde o il için personel yaş ortalaması görüntülenebilmektedir ve herhangi bir il seçildiğinde o ile ait yaş aralığı ve cinsiyet bazında personel sayısı grafiğgi, cinsiyete göre personel dă̆ılımı grafiği ve o ildeki personel yaş ortalaması görseli detaylandırılabilir. Personel yaş ortalamasına göre dağılım haritasında yaş ortalamasııın en fazla Bartın ilinde olduğu görülmektedir. Yaş ortalamasına göre değerlendirecek olursak ilerde emekli olacak personeller de göz önünde bulundurulursa Bartın iline personel gerekebileceği değerlendirilmesinde bulunulabilir. Buna göre ileride yapılacak personel alımında bu durum dikkate alınabilir.

Şekil 2. Personel yaş ortalaması raporu

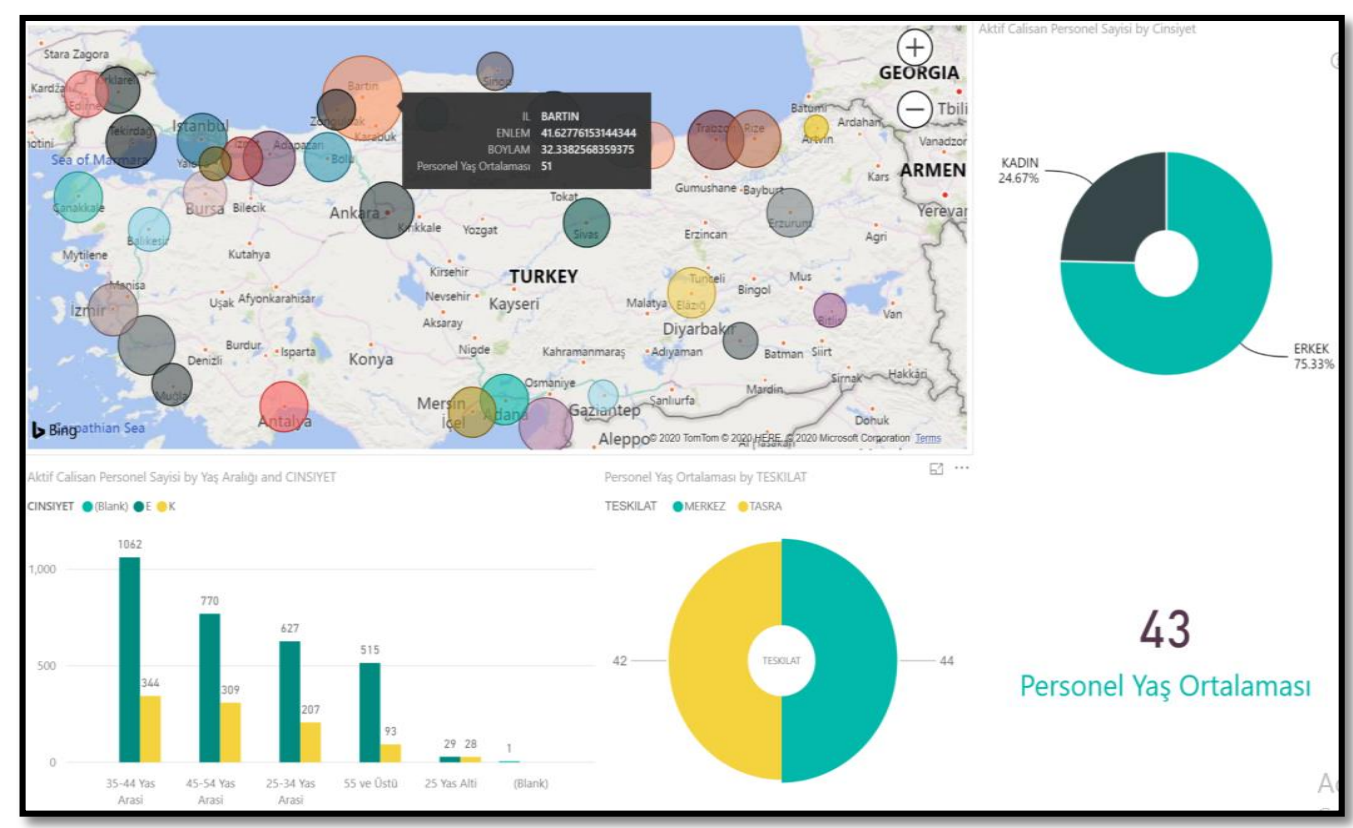




\subsection{Anket Verileri}

Personel Karar Destek sistemi için yapılan veri madenciliği uygulamasında bir devlet kurumunda yapılan İç Kontrol Sistemi anketi verileri kullanılmıştır. İç kontrol sistemi anketinde personele çeşitli dallarda sorular sorulmuştur. Bu sorular içerisinde 3 çeşit gruplandırma yapılmıştır. Anket soruları Tablo 2, Tablo 3 ve Tablo 4.’te verilmiştir.

1. grupta; kadro pozisyonu, eğitim ve hizmet bilgileri yer almaktadır.

2. grupta; çalışılan birim ile ilgili işleyiş ve çalışanların memnuniyetine ilişsin bilgiler yer almaktadır.

3. grupta; bağlı olunan yönetici ve memnuniyet ile ilgili bilgiler yer almaktadır.

\section{Tablo 2. Anket verileri (1. grup)}

\section{Soru}

Kardo Pozisyonu

Organization

Eğitim Durumu

Kamuda çalışma süresi

\section{Cevap 1}

Yönetici

Center

İlköğretim

6 y1l<

\section{Cevap 2}

Şube Müdürü ve üstü

Provincial

Lise Önlisans

6-10 y1l
Cevap 3

Diğer Personel

11-20 y1l
Cevap 4

Lisans ve Üstü

$>20$ y1l

\section{Bölüm 1 Sorulart}

Çalıştığım birimden memnunum (Kesinlikle Katılıyorum, Katılıyorum, Fikrim Yok, Katılmıyorum,

Kesinlikle Katılmıyorum)

Birim içinde yetki belirsizlikleri yoktur.

Başka iş unvanlarında çalışma talepleri değerlendirmeye alınır.

Değişken Adı

Adil bir takdir ve ödüllendirme sistemi vardır

Çalışanlara mesleki gelişimlerini sağlamak üzere mevcut görevleri dışındaki projelerde de çalışma

firsat1 verilir.

Çalışanların motivasyonu için sosyal etkinlikler ve eğitimler düzenlenir.

Çalışma ortamındaki fiziki koşullar uygundur.

Çalışanlar arasında samimiyete dayalı ilişkiler vardır.

Yürütülen işlerin gerektirdiği teknik eğitimler verilmektedir.

Birim içindeki bölümler arasında iletişim ve koordinasyon sistemi etkili biçimde işlemektedir.

Birimimde hedeflerle çalışma anlayışı vardır.

Birim hedef ve öncelikler belirlenirken çalışanların görüşüne başvurulur.

Birim hedeflerine ulaşma düzeyi belirli aralıklarla izlenmektedir.

Birim hedeflerine ulaşmada sapmalar belirlendiğinde önlem alınmaktadır.

İşin gerektirdiği evraklara kolaylıkla ulaşabilmemi sağlayan bir arşiv sistemi vardır

İşlerin yürütülmesinde yazılı kurallara ve talimatlara uygun hareket edilir.

MEMNUNIYET

B1S02

B1S03

B1S04

B1S05

B1S06

B1S07

B1S08

B1S09

B1S10

B1S11

B1S12

B1S13

B1S14

B1S15

B1S16

\section{Tablo 4. Anket verileri (3. grup)}

Bölüm 2 Soruları

Yöneticim yapılan işi izler, sonucunu değerlendirir ve çalışanları yönlendirir.

Yöneticimin beni bir birey olarak önemsediğini hissediyorum.

Yöneticim yaptığım işle ilgili inisiyatif kullanabilme ortamını sağlar.

Yöneticim birimimiz ile ilgili önemli gelişmeler hakkında çalışanları bilgilendirir.

Yöneticim personelin bilgi ve becerisini geliştirmesini destekler.

Yöneticim personelin çalışmasını, katkılarını takdir ederken adaletli davranır.

Yöneticim yapılan işlerin sonucu ile ilgili tüm sorumluluğu üstlenir.

Yöneticim önemsiz ayrıntılarla ilgilenmez ve bütünü kolay görebilir.

Yöneticim önemli kararlar vermeden önce çalışanların düşünce ve önerilerini almaktadır.

İş paylaşımı adil bir şekilde yapılır.

Çalışanlara yetki devri (yöneticiye vekâlet etme) objektif bir şekilde yapılmaktadır.

Bilgi ve yeteneklerime uygun işte/işlerde çalışıyorum.

Yürütülen işlerle ilgili bilgi paylaşımı yapılmaktadır.

İş unvanlarına ilişkin görev, yetki ve sorumluluklar net olarak belirlenmiştir.

İşlerin yürütülmesinde yazılı kurallara ve talimatlara uygun hareket edilir.
Değişken Adı

B2S01

B2S02

B2S03

B2S04

B2S05

B2S06

B2S07

B2S08

B2S09

B2S10

B2S11

B2S12

B2S13

B2S14

B2S15 
Bölüm 1 ve Bölüm 2 anket sorularının cevapları "Kesinlikle Katılıyorum, Katılıyorum, Fikrim Yok, Katılmıorum, Kesinlikle Katılmıyorum" şeklindedir. Anket verileri düzenlenirken "Bölüm Kodu - Soru Numarası" şeklinde kodlanarak veri madenciliği uygulaması için uygun hale getirilmiştir. Örneğin 1. Bölüm sorularından 1. Soru için anket yanıtı "B1S01" şeklinde kodlanmıştır. Ayrıca csv formatında tutulan veriler WEKA içerisinde kullanılan ARFF (Attribute-Relation File Format) dosya formatı dönüştürülmüştür. İ̧ kontrol sistemi anketi veri seti merkez teşkilatında 925, taşra teşkilatında 1001, toplamda 1926 kayıttan oluşmaktadır.

\subsection{K-Means Algoritması}

Kümeleme analizi nesnelerden benzer özellikte olanların aynı kümeler içinde toplandığı bir gruplama sürecidir. Bir küme, aynı küme içinde diğer nesneler ile benzer özellikleri gösteren nesneler topluluğudur. Benzer özellikleri göstermeyen nesneler farklı kümelerde gruplanır. Kümeleme analizinde temel amaç küme içi benzerliği maksimum yapmak, kümeler arası benzerliği minumum yapmaktır.

K-Means algoritması 1967 yılında MacQueen tarafindan sunulmştur. Bu algoritmada k adet küme oluşmaktadır ve her küme içerisinde bulunan verilerin ağırlıklı ortalamaları sonucu bir değer ortaya çıkar. Küme içerisinde bu değere en yakın olan nokta değeri küme merkezi (centroid) olarak kabul edilir (MacQuen, 1967). İlk önce k sayıda rastgele nokta belirlenir. Bu noktalar ilk küme merkezleri olarak atanır. Daha sonra gelen her veri değeri merkez noktaya en yakın olduğu kümeye dahil edilir. Eklendiği küme elemenlarının ağırlıklı ortalamaları tekrar hesaplanır ve yeni bir küme merkezi değeri bulunur. Küme üyelikleri değişene kadar bu devam eder. Küme sayısı belirli degil ise deneme yoluyla en uygun sayı bulunur.

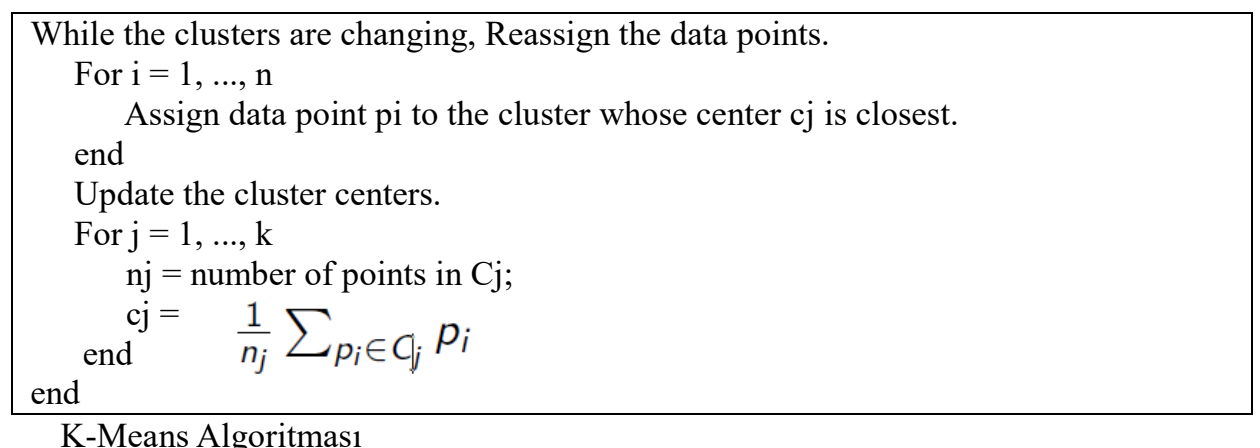

\subsection{Apriori Algoritması}

Apriori algoritması, sık kullanılan öğe kümelerini ve çeşitli öğe kümeleri arasındaki ilişkiyi bulmak ve veri kümesinde tekrarlanan modelleri keşfetmek için uygulanan bir algoritmadır.

Apriori algoritması, Agrawal ve Srikant (Agrawal ve Srikant, 1994) tarafından 1994 yılında geliştirilmiş̧ir. Bu algoritma en yaygın kullanılan ve bilinen birliktelik kuralı çıkarım algoritmasıdır. Apriori algoritmasına göre, "Eğer k-öğe kümesi minimum destek kriterini sağlıyorsa, bu kümenin alt kümeleri de minimum destek kriterini sağlar.” şeklindedir. Öğe küme, bir veya daha fazla elemandan oluşan kümedir. k-öğe küme (k-itemset) ise içinde k adet öğe bulunan kümedir. Apriori, $(k+1)$ sık geçen öğe kümesini bulmak için en sık geçen öğe kümesine ihtiyaç duymaktadır. Sık geçen öğe kümelerini bulmak için öncelikle olarak minimum destek kriterini sağlayan sık geçen öğe kümesi bulunarak işlem yapılır. Bu süreç, algoritma sık geçen öğe kümeleri bulamayıncaya kadar devam eder (Matei, 2010).

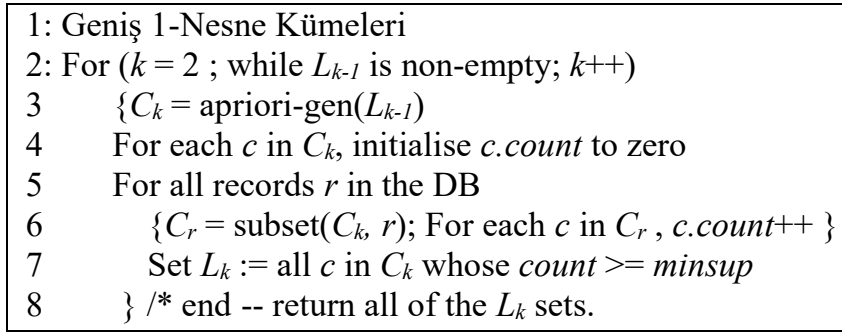

Apriori Algoritmas1

A ve B, birbirinden farklı birer öğe küme olsun. A öğe kümesi için destek, A öğe kümesini kapsayan kümelerin tüm öğe kümelere oranıdır ve (1) denklemi ile hesaplanır. A ve B öğe kümeleri için destek ise tüm kümeler içerisinde birlikte bulunma olasılığıdır ve (2) denklemi ile elde edilir. B öğe kümesinin hangi olasılıkla A öğe kümeleri içerinde bulunacağı güven değeri ile ifade edilir ve (3) ve (4) denklemlerinden biri ile hesaplanır.

$$
\text { Support }(A)=\frac{\text { Number of } \text { A sets of items }}{\text { Total sets of items }}
$$




$$
\begin{aligned}
& \text { Support }(A, B)=\frac{\text { Number of }(A, B) \text { sets of items }}{\text { Total sets of items }} \\
& \text { Confidence }(A, B)=\frac{\text { Number of }(A, B) \text { sets of items }}{\text { Number of A sets of items }} \\
& \text { Confidence }(A)=\frac{\operatorname{Support}(A, B)}{\operatorname{Support}(A)}
\end{aligned}
$$

Elde edilen kuralların kullanışlılığı, doğruluğu ve güvenilirliği, destek ve güven kriterleri ile belirlenir. İki öğe kümenin birlikteliğinin önemli olması için hem destek hem de güven kriterlerinin olabildiğince yüksek olması gerekmektedir.

\section{Araştırma Sonuçları ve Tartışma}

\subsection{Kümeleme Algoritması Sonuçları}

Bu çalışmada İç Kontrol Sistemi anketine verilen cevaplar neticesinde kümeleme yöntemi ile segmentasyon çalışması yapılmıştır. Segmantasyon ile personelin anket sorularına verdiği cevaplar detaylı incelenerek memnuniyet durumu analizi etkili ve doğru bir şekilde yapılabilir. Ayrıca personelin memnuniyet durumuna göre farklı gruplara ayrıldığı görülebilir. Hangi gruba nasıl yaklaşılması gerektiği, nasıl hitap edilmesi gerektiği belirlenebilir. Her grubun memnuniyet durumunun farklılaşan noktaları belirlenerek, stratejiler ve uygulama faaliyetleri bu grubun ihtiyacına göre planlanabilir.

$\mathrm{Bu}$ çalışmada benzer verilerin gruplanması/kümelenmesi yoluyla personel segmentasyonu yapılması amaçlandığı için kümeleme modeli kullanılmıştır. Kümeleme analizinde amaç, küme içindeki verilerin birbirlerine çok benzemesi, fakat küme özellikleri birbirlerinden çok farklı olması ve veri tabanındaki verilerin bu farklı kümelere bölünmesidir (Akpınar, 2000).

Uygulamada, kümeleme analizi yöntemlerinden K-Means algoritması kullanılmıştır. K-Means algoritmasının tercih edilmesinin sebebi küme sayısının parametrik olması, uygulanmasının kolay olması ve hızlı çalısması, kategorik verilerle çalışacak şekilde adapte edilebilmesidir.

K-Means algoritması ile yapılan analizler sonucunda veri kümesi için en uygun küme sayısının 4 olduğu tespit edilmiştir. Uzaklık fonksiyonu (distanceFunction) olarak "Euclidean Distance" seçilmiştir. K-Means algoritması uygulanarak elde edilen 4 kümenin profili

\begin{tabular}{|c|c|c|c|c|}
\hline Değişken & Küme 1 & Küme 2 & Küme 3 & Küme 4 \\
\hline Teckilat & Tacra & Merkez & Tacra & Tacra \\
\hline Eğitim & Lisans veya üstü & Lisans veya üstü & 20 yıl üzeri & Lisans veya üstü \\
\hline Hizmet & 20 yıl üzeri & 20 yıl üzeri & 20 y1l üzeri & $6-10$ yil \\
\hline Memnuniyet & Memnun & Memnun & Memnun Değil & Memnun \\
\hline B1S02 & Memnun & Memnun & Memnun Değil & Memnun \\
\hline B1S03 & Fikri Yok & Memnun & Memnun Değil & Memnun Değil \\
\hline B1S04 & Memnun Değil & Memnun & Memnun Değil & Memnun Değil \\
\hline B1S05 & Memnun Değil & Memnun & Memnun Değil & Memnun Değil \\
\hline B1S06 & Memnun Değil & Memnun & Memnun Değil & Memnun Değil \\
\hline B1S07 & Memnun & Memnun & Memnun Değil & Memnun \\
\hline $\mathrm{B} 1 \mathrm{~S} 08$ & Memnun & Memnun & Memnun Değil & Memnun \\
\hline B1S09 & Memnun Değil & Memnun & Memnun Değil & Memnun Değil \\
\hline B1S10 & Fikri Yok & Memnun & Memnun Değil & Memnun \\
\hline B1S11 & Fikri Yok & Memnun & Memnun Değil & Memnun \\
\hline $\mathrm{B} 1 \mathrm{~S} 12$ & Memnun Değil & Memnun & Memnun Değil & Memnun Değil \\
\hline B1S13 & Fikri Yok & Memnun & Memnun Değil & Fikri Yok \\
\hline B1S14 & Fikri Yok & Memnun & Memnun Değil & Memnun \\
\hline $\mathrm{B} 1 \mathrm{~S} 15$ & Memnun & Memnun & Memnun Değil & Memnun \\
\hline B1S16 & Memnun & Memnun & Memnun Değil & Memnun \\
\hline B2S01 & Memnun & Memnun & Memnun Değil & Memnun \\
\hline $\mathrm{B} 2 \mathrm{~S} 02$ & Memnun & Memnun & Memnun Değil & Memnun \\
\hline $\mathrm{B} 2 \mathrm{~S} 03$ & Fikri Yok & Memnun & Memnun Değil & Memnun \\
\hline B2S04 & Memnun & Memnun & Memnun Değil & Memnun \\
\hline $\mathrm{B} 2 \mathrm{~S} 05$ & Fikri Yok & Memnun & Memnun Değil & Memnun Değil \\
\hline B2S06 & Fikri Yok & Memnun & Memnun Değil & Memnun Değil \\
\hline B2S07 & Fikri Yok & Memnun & Memnun Değil & Memnun Değil \\
\hline $\mathrm{B} 2 \mathrm{~S} 08$ & Fikri Yok & Memnun & Memnun Değil & Memnun Değil \\
\hline $\mathrm{B} 2 \mathrm{~S} 09$ & Fikri Yok & Memnun & Memnun Değil & Memnun Değil \\
\hline $\mathrm{B} 2 \mathrm{~S} 10$ & Fikri Yok & Memnun & Memnun Değil & Memnun Değil \\
\hline B2S11 & Fikri Yok & Memnun & Memnun Değil & Memnun Değil \\
\hline $\mathrm{B} 2 \mathrm{~S} 12$ & Fikri Yok & Memnun & Memnun Değil & Memnun \\
\hline $\mathrm{B} 2 \mathrm{~S} 13$ & Memnun & Memnun & Memnun Değil & Memnun \\
\hline B2S14 & Fikri Yok & Memnun & Memnun Değil & Memnun \\
\hline $\mathrm{B} 2 \mathrm{~S} 15$ & Fikri Yok & Memnun & Memnun Değil & Memnun \\
\hline
\end{tabular}
aşağıdaki Tablo 5 'te verilmiştir.

Tablo 5. K-Means algoritması sonuçları

K-Means algoritması uygulanarak elde edilen 4 küme aşağıda açıklanmışır. 
Küme 1: Tüm veri setinin \%16'sını oluşturmaktadır. 307 kayıt 1. Kümede toplanmıştır. 1. Kümenin özellikleri taşra teşkilatında çalışan 20 yıl üstü hizmeti olan ve lisans veya üstü ögrenimi olan çalıştı̆̆ biriminden memnun olan kişilerden oluşmaktadır. Bu grubu oluşturan personel genel olarak çalıştı̆̆ birimden memnundur. Fakat adil bir takdir ve ödüllendirme sistemi olmadığını, çalışanlara mesleki gelişimlerini sağlamak üzere mevcut görevleri dışındaki projelerde de çalışma firsatı verilmediğini, çalışanların motivasyonu için sosyal etkinlikler ve eğitimler düzenlenmediğini ve birim hedef ve öncelikler belirlenirken çalışanların görüşüne başvurulmadığını düşünmektedirler. Ayrıca bu gruptaki personel bağlı olduğu üst yöneticisi hakkında genel olarak fikir beyan etmekten kaçınmıştır.

Küme 2: Tüm veri setinin \%52'sini oluşturmaktadır. 984 kayıt 2. Kümede toplanmıştır. 2. Kümenin özellikleri merkez teşkilatında çalışan 20 yıl üstü hizmeti olan ve lisans veya üstü öğrenimi olan çalıştığı biriminden memnun olan kişilerden oluşmaktadır. Dört küme içerisinde en çok 2. Kümede kayıtlar gruplanmıştır. Yani çalışan personelin büyük çoğunluğu çalıştı̆ı birimden, işleyişten ve yöneticisinden memnundur denilebilir. Özellikle Merkez teşkilatında memnuniyet oranı daha fazladır.

Küme 3: Tüm veri setinin $\% 22$ 'sini oluşturmaktadır. 423 kayıt 3. Kümede toplanmıştır. 3. Kümenin özellikleri taşra teşkilatında çalışan 20 yıl üstü hizmeti olan ve lisans veya üstü öğrenimi olan çalıştığı biriminden memnun olmayan pesonelden oluşmaktadır. Yani taşra teşkilatında 20 yıl üzeri hizmeti olan personel çalıştı̆̆ birimden, işleyişten ve yöneticisinden genel olarak memnun değildir denilebilir.

Küme 4: Tüm veri setinin \%10’unu oluşturmaktadır. 180 kayıt 4. Kümede gruplanmıştır. 4. Kümenin özellikleri taşra teşkilatında çalışan 6 ve 10 yıl arası hizmeti olan ve lisans veya üstü öğrenimi olan çalıştı̆ı biriminden memnun olan pesonelden oluşmaktadır. Bu kümede toplanan personel 1. Kümedeki gibi adil bir takdir ve ödüllendirme sistemi olmadığını, çalışanlara mesleki gelişimlerini sağlamak üzere mevcut görevleri dışındaki projelerde de çalışma firsatı verilmediğini, çalışanların motivasyonu için sosyal etkinlikler ve eğitimler düzenlenmediğini ve birim hedef ve öncelikler belirlenirken çalışanların görüşüne başvurulmadığını düşünmektedirler. Ayrıca bu gruptaki personel bağlı olduğu üst yöneticisi hakkında genel olarak memnun olmadığını bildirmişlerdir.

Veri setinin yaklaşık \%50'sini oluşturan 2. Kümede, merkez teşkilatında çalışan 20 yıl üstü hizmeti olan personel çalıştı̆ı birimden memnundur diyebiliriz. Fakat 3. Kümedeki taşra teşkilatında 20 yıl üstü hizmeti olan personel çalıştı̆ı̆ birimden memnun olmadığı ortaya çıkmıştır. Bu personel için şartların iyileştirilmesi ya da görevde yükselme gibi firsatlar personelin memnuniyeti artırabilir. Taşra teşkilatında personel emekli olduktan sonra yerlerine daha genç personel alımı yapılabilir. Taşra teşkilatında yaş ortalaması yüksek olduğundan genç personel sayısının artırılması gerekmektedir. Birinci ve dördüncü kümedeki taşra teşkilatında çalışıp 20 yıl üzeri ve 6 - 10 yıl arası hizmeti olan personeller çalıştı̆̆ birimden memnun, ama birim işleyişindeki benzer konulardan memnun değillerdir. Takdir ve ödüllendirme sisteminin iyileştirilmesi, mevcut görevleri dışındaki projelerde de çalışma imkanı sağlanması, sosyal etkinlikler ve eğitimler düzenlenmesi ve çalışanların görüşüne başvurulması gibi iyileştirmeler yapılarak bu gruptaki personelin memnuniyeti artır1labilir.

\subsection{Apriori Algoritması Sonuçları}

Bu çalışmada bir devlet kurumunda çalışan personelin İç Kontrol Sistemi anket sorularına vermiş olduğu cevaplar arasında anlamlı ilişkileri bulmak, bu ilişkilerden faydalanarak personelin çalıştı̆̆ birimden menuniyetini karş̧laştırarak anlamlı sonuçlar elde etmek ve çalışılan birimden memnun olmama nedenlerini keşfetmek için Apriori algoritması kullanılmıştır.

$\mathrm{Bu}$ çalışmada apriori algoritması ile birimden memnun olmama durumu incelendiği için 1926 kayıtlı veri setinin hepsi kullanılmamıştır. $\mathrm{Bu}$ veri seti içinden çalıştığı birimden memnun olmayan yani "Çalıştı̆ı̆m birimden memnunum" sorusuna "Katılmıyorum" ve "Kesinlikle Katılmıyorum" cevabını veren 330 kayıt alınarak analiz yapılmıştır. Tablo 6.'da apriori algoritması parametre seçimleri ve Tablo 7'de apriori algoritması sonucunda oluşan kurallar verilmiş̧ir.

Tablo 6. Apriori algoritmast parametreleri

\begin{tabular}{|l|l|}
\hline Metric Type & Confidence \\
\hline Min Metric & 0.7 \\
\hline Class Index & 4 \\
\hline Num Rules & 20 \\
\hline Lower Bound Min Support & 0.1 \\
\hline Upper Bound Min Support & 1 \\
\hline
\end{tabular}


Tablo 7. Apriori algoritması sonuçları

\begin{tabular}{|c|c|c|c|c|c|c|c|c|}
\hline Kurallar & $\begin{array}{l}\text { Best rules } \\
\quad(\mathrm{X} 1)\end{array}$ & $\begin{array}{l}\text { Best Rule } \\
\text { (X2) }\end{array}$ & $\begin{array}{l}\text { Support } \\
(\mathrm{X} 1, \mathrm{X} 2)\end{array}$ & Satisfaction & $\begin{array}{c}\text { Support } \\
(\mathrm{X} 1, \mathrm{X} 2, \mathrm{Y})\end{array}$ & Confidence & Lift & $\begin{array}{l}\text { Convicti- } \\
\text { on }\end{array}$ \\
\hline Kural 1 & $\begin{array}{c}\text { B1S04=MEMNUN } \\
\text { DEĞİL }\end{array}$ & - & 295 & MEMNUN DEĞİL & 295 & 1 & 1 & 0 \\
\hline Kural 2 & $\begin{array}{c}\text { B1S06= MEMNUN } \\
\text { DEĞİL }\end{array}$ & - & 283 & MEMNUN DEĞİL & 283 & 1 & 1 & 0 \\
\hline Kural 3 & $\begin{array}{c}\text { B1S12= MEMNUN } \\
\text { DEĞİL }\end{array}$ & - & 280 & MEMNUN DEĞİL & 280 & 1 & 1 & 0 \\
\hline Kural 4 & $\begin{array}{c}\text { B1S05= MEMNUN } \\
\text { DEĞİL }\end{array}$ & - & 272 & MEMNUN DEĞİL & 272 & 1 & 1 & 0 \\
\hline Kural 5 & $\begin{array}{c}\text { B1S09= MEMNUN } \\
\text { DEĞİL }\end{array}$ & - & 268 & MEMNUN DEĞİL & 268 & 1 & 1 & 0 \\
\hline Kural 6 & $\begin{array}{c}\text { B1S04= MEMNUN } \\
\text { DEĞİL }\end{array}$ & $\begin{array}{l}\text { B1S06= } \\
\text { MEMNUN } \\
\text { DEĞİL }\end{array}$ & 265 & MEMNUN DEĞİL & 265 & 1 & 1 & 0 \\
\hline Kural 7 & $\begin{array}{c}\text { B1S04= MEMNUN } \\
\text { DEĞİL }\end{array}$ & $\begin{array}{l}\text { B1S12= } \\
\text { MEMNUN } \\
\text { DEĞİL }\end{array}$ & 265 & MEMNUN DEĞİL & 265 & 1 & 1 & 0 \\
\hline Kural 8 & $\begin{array}{c}\text { B1S12 }=\text { MEMNUN } \\
\text { DEĞİL }\end{array}$ & - & 280 & $\begin{array}{c}\text { B1S04= MEMNUN } \\
\text { DEĞIL }\end{array}$ & 265 & 0.95 & 1.06 & 1.86 \\
\hline Kural 9 & MEMNUN DEĞİL & $\begin{array}{l}\text { B1S12= } \\
\text { MEMNUN } \\
\text { DEĞİL }\end{array}$ & 280 & MEMNUN DEĞİL & 265 & 0.95 & 1.06 & 1.86 \\
\hline Kural 10 & $\begin{array}{c}\text { B1S12= MEMNUN } \\
\text { DEĞİL }\end{array}$ & - & 280 & $\begin{array}{c}\text { MEMNUN DEĞİL } \\
\text { B1S04= MEMNUN } \\
\text { DEĞILL }\end{array}$ & 265 & 0.95 & 1.06 & 1.86 \\
\hline
\end{tabular}

Tablo 7’de Apriori algoritması sonucuna göre çıkan en iyi 10 kural göre:

Kural 1: Adil bir takdir ve ödüllendirme sistemi olmadığını düşünen personelin \%100’ü (conf:1) çalıştı̆̆ birimden memnun değildir. Adil bir takdir ve ödüllendirme sisteminden memnun olup olmama durumu çalışllan birimden memnuniyeti belirlemede rolü vardır diyebiliriz. 1. Kural en fazla birlikteliği olan kurallardan biridir.

Adil bir takdir ve ödüllendirme sisteminden memnun olmama durumunda çalışılan birimden memnun olmama \%100 (confidence) değerinde olduğu; Adil bir takdir ve ödüllendirme sisteminden memnun olmama durumunda çalışılan birimden memnun olmaması 1 (lift) kat arttı̆̆1; Adil bir takdir ve ödüllendirme sisteminden memnun olmama durumunda çalışılan birimden memnun olmama durumunun birbirleri ile ilişkili (conviction) olduğunu söyleyebiliriz. Support değerinin 295 olması bu kuralın tüm kural seti içerisinde 295 defa birlikte görüldüğ̈̈nü ifade etmektedir.

Kural 2: Çalışanların motivasyonu için sosyal etkinlikler ve eğitimler düzenlenmediğini düşünenlerin \%100'ü (conf: 1) çalıştığ1 birimden memnun değildir. Çalışanların motivasyonu için sosyal etkinlikler ve eğitimler yeterince düzenlenip düzenlenmemesi çalışılan birimden memnuniyeti belirlemede rolü vardır.

Kural 3: Birim hedef ve öncelikler belirlenirken çalışanların görüşüne başvurulmadığını düşünenlerin \%100'ü (conf: 1) çalıştığı birimden memnun değildir. Birim hedef ve öncelikler belirlenirken çalışanların görüşüne başvurulup başvurulmaması çalışılan birimden memnuniyeti belirlemede rolü vardır. Birim hedef ve öncelikler belirlenirken çalışanların görüşüne başvurulmaması çalışılan birimden memnun olunmaması durumunun birbirleri ile ilişkili (conviction) olduğunu söyleyebiliriz.

Kural 4: Çalışanlara mesleki gelişimlerini sağlamak üzere mevcut görevleri dışındaki projelerde de çalışma firsatı verilmediğini düşünenlerin \%100’ü (conf: 1) çalıştığı birimden memnun değildir. Çalışanlara mesleki gelişimlerini sağlamak üzere mevcut görevleri dışındaki projelerde de çalışma firsatı verilip verilmemesi çalışılan birimden memnuniyeti belirlemede rolü vardır.

Kural 5: Yürütülen işlerin gerektirdiği teknik eğitimler verilmediğini düşünenlerin \%100’ü (conf: 1) çalıştığı birimden memnun değildir. Yürütülen işlerin gerektirdiği teknik eğitimler verilip verilmemesi çalışılan birimden memnuniyeti belirlemede rolü vardır.

Kural 6: Adil bir takdir ve ödüllendirme sistemi olmadığını ve çalışanların motivasyonu için sosyal etkinlikler ve eğitimler düzenlenmediğini düşünenlerin \%100’ü (conf: 1) çalıştı̆̆ birimden memnun değildir. Adil bir takdir ve ödüllendirme sisteminin olup olmaması ve çalışanların motivasyonu için sosyal etkinlikler ve eğitimlerin düzenlenip düzenlenmemesi çalışılan birimden memnuniyeti belirlemede rolü vardır.

Kural 7: Adil bir takdir ve ödüllendirme sistemi olmadığını ve birim hedef ve öncelikler belirlenirken çalışanların görüşüne başvurulmadığını düşünenlerin \%100'ü (conf: 1) çalıştı̆̆ birimden memnun değildir. Adil bir takdir ve ödüllendirme sisteminin olup 
olmadığı ve birim hedef ve öncelikler belirlenirken çalışanların görüşüne başvurulup başvurulmaması çalışılan birimden memnuniyeti belirlemede rolü vardır.

Kural 8: Birim hedef ve öncelikler belirlenirken çalışanların görüşüne başvurulmadığını düşünenlerin \% $\% 95$ 'i (conf: 0.95 ) adil bir takdir ve ödüllendirme sisteminin olmadığını bildirmişlerdir. Birim hedef ve öncelikler belirlenirken çalışanların görüşüne başvurulup başvurulmaması adil bir takdir ve ödüllendirme sisteminden memnuniyeti belirlemede rolü vardır.

Kural 9: Çalıştı̆ı birimden memnun olmayanlar ve birim hedef ve öncelikler belirlenirken çalışanların görüşüne başvurulmadığını düşünenlerin \%95'i (conf: 0.95 ) adil bir takdir ve ödüllendirme sisteminin olmadığını bildirmişlerdir. Çalışılan birimden memnun olup olmama durumu ve birim hedef ve öncelikler belirlenirken çalışanların görüşüne başvurulup başvurulmaması adil bir takdir ve ödüllendirme sisteminden memnuniyeti belirlemede rolü vardır.

Kural 10: Birim hedef ve öncelikler belirlenirken çalışanların görüşüne başvurulmadığını düşünenlerin \%95’i (conf: 0.95) adil bir takdir ve ödüllendirme sisteminin olmadığını ve çalışı̆ğı birimden memnun olmadığını bildirmiştir. Birim hedef ve öncelikler belirlenirken çalışanların görüşüne başvurulup başvurulmaması adil bir takdir ve ödüllendirme sisteminden ve çalışlan birimden memnuniyeti belirlemede rolü vardır.

Sonuçlardan görüldüğü gibi veri madenciliği birliktelik analizi yöntemlerinden apriori algoritması ile personelin çalıştı̆̆ birimden memnun olmamasının nedeni en çok adil bir takdir ve ödüllendirme sisteminin olmaması, çalışanların motivasyonu için sosyal etkinlikler ve eğitimler düzenlenmemesi ve birim hedef ve öncelikler belirlenirken çalışanların görüşüne başvurulmaması ile ilişkili olduğu tespit edilmiştir. Karar vericiler ve yöneticiler bu faktörleri göz önünde bulundurarak ve gerekli önlemleri alarak birim içinde ve devlet kurumunda çalışma memnuniyetinde artış sağlanabilir.

\section{Sonuç}

$\mathrm{Bu}$ çalışmada bir devlet kurumunun personel verileri üzerinde iş zekası ve veri madenciliği süreçleri gerçekleştirilerek örnek uygulama yapılmıştır. Personele ait verilerin yönetimini sağlamak, iş ve işlemlerini kolaylaştırmak, personel alım stratejisi planlamasına katkı sağlamak ve kullanıcıların dinamik olarak veri analizi yapabilmesi için bir karar destek sistemi oluşturmak amaçlanmıştır. Ayrıca İç Kontrol Sistemi anket verilerinden anlamlı ve yararlı bilgiler elde etmek ve bu bigiler ışığında personel karar destek planlama faaliyetlerinde destek olmak amaçlanmıştır. Birliktelik kuralı çıkarım algoritmalarından biri olan Apriori algoritmsı ve kümeleme yöntemlerinden K-Means algoritması ile İç Kontrol Sistemi anketi verilerinde yola çıkarak personelin çalıştığı birimden memnuniyet analizi yapılmıştır.

Çalışmaya konu olan devlet kurumunun personel bilgi sisteminde statik bir şekilde oluşturulan raporlar ve istatistikler mevcuttur ve personel verileri ile dinamik analiz yapamamaktadır. Bu nedenden dolayı iş zekası ve veri madenciliği çözümleri ile kullanıcıların dinamik bir şekilde analiz yapabileceği personel karar destek sistemi oluşturulmuştur. Personel karar destek sistemi ile personel verilerini istatistiksel olarak sunabilmek, bu verileri analiz edebilmek ve detaylı inceleyebilmek, karar verici konumunda bulunan kişilerin gelecek tahminlerine katkı sağlamak amaçlanmıştır.

Bu çalışmada iç geçerlilik ile ilgili tehdit, k-means algoritmasında başlangıç $\mathrm{k}$ adet küme sayısı seçiminin deneme yanılma yoluyla belirlenmesidir. Kümeleme sonucunu doğrudan etkileyen optimal bir k değeri seçimi için hala daha güvenilir ve hızlı yöntemlere ihtiyaç duyulmaktadır. K-Means popüler bir yöntem olmakla birlikte son yıllarda $\mathrm{k}$ parametresi bakımından iyi sonuçlar verdiği bilinen Xortalamalar, G-ortalamalar gibi yöntemler ileriki çalışmalarda kullanılabilir. Ayrıca sadece 2019 yılına ait anket verileri olması önceki yıllara ait verilerin olmaması iç geçerlilik tehditi olarak görülmüştür.

Dış geçerlilik sonuçların ne kadar genelleştirilebilir olduğunu ifade eder. İş zekası ve veri madenciliği ile geliştirilen karar destek sistemi dış dünyadaki diğer problemlere de kolaylıkla uygulanabilir. Bu çalışmanın dış geçerliliğini tehdit eden faktör ise WEKA'nın Power BI uygulaması ile entegre olmayıp veri madenciliği ile iş zekası uygulamasının ayrı çalışmasıdır. İleriki çalışmalarda tek bir sistem üzerinden karar destek sistemi geliştirilmesi için Power BI'ın Python entegrasyonu yardımıyla veri madenciliği uygulaması geliştirilebilir.

Yapı geçerliliği, çalışmanın amaçlanan yapıyı ölçüp ölçmediği, gözlemler veya ölçümler temelinde yapılan çıkarımların uygunluğudur. $\mathrm{Bu}$ çalışmada personel karar destek sistemi oluşturmak amaçlanmıştır. Oluşturulan iş zekası sistemi ile kullanıcılar dinamik olarak veri analizi yapabilir ve stratejik hedeflere ulaşabilmek adına daha hızlı ve doğru kararlar üretilebilir.

\section{Kaynakça}

Agrawal, R. and Srikant, R. (1994). Fast Algorithms for Mining Association Rules in Large Databases. Proceedings of the 20th International Conference on Very Large Databases (VLDB), pp. 487-499, Santiago.

Akpınar, H. (2000). Veri Tabanlarında Bilgi Keşfi ve Veri Madenciliği. İstanbul Üniversitesi İşletme Fakültesi Dergisi, 29(1), 1-22.

Al-Radaideh, Q. A. ve Al Nagi, E. (2012). Using Data Mining Techniques to Build a Classification Model for Predicting Employees Performance. International Journal of Advanced Computer Science and Applications, 3(2), 144-150.

Chien, C. ve Chen, L. (2008). Data mining to improve personnel selection and enhance human capital: A case study in high-technology industry, Expert Systems with Applications, 34(1), pp. 280-290. 
Eren, A. (2018). İş zekası sistemlerinin performans ve karar verme üzerine etkileri, Doktora Tezi, Atatürk Üniversitesi Sosyal Bilimler Enstitüsü, pp. 153-164, Erzurum.

Gupta, S. K., Nadia, R., Sipahi, E., Teston, S. F. ve Fantaw, A. (2020). Analysis of the Effect of Compensation on Twitter Based on Job Satisfaction on Sustainable Development of Employees Using Data Mining Methods. International Research Association for Talent Development and Excellence, 12(3), 3289-3313.

Jung, Y. ve Suh, Y. (2019). Mining the voice of employees: A text mining approach to identifying and analyzing job satisfaction factors from online employee reviews. Decision Support Systems, vol. 123, pp-1-12.

Langit, L., Goff, K. S., Mauri, D., Malik, S. ve Welch, J. (2009). Smart Business Intelligence Solutions with Microsoft SQL Server 2008, Microsoft, pp. 5-8, Washington.

Lin, Y. H., Tsai, K. M., Shiang, W. J., Kuo, T. C. ve Tsai, C. H. (2009). Research on using ANP to establish a performance assessment model for business intelligence systems. Expert Systems with Applications, 36(2), pp. 4135-4146.

MacQueen, J. (1967). Some methods for classification and analysis of multivariate observations. In: Fifth Berkeley Symposium on Mathematics. Statistics and Probability. University of California Press, pp. 281-297.

Matei, G. (2010). A collaborative approach of Business Intelligence systems. Journal of Applied Collaborative Systems, 2(2), 91-101.

Michael, H. B. (1999). Business Intelligence Value Chain, DM Review.

Negash, S. (2004). Business intelligence. Communications of the AIS, 13(1), pp. 177-195.

Shen, Y. (2007). A Formal Ontology for Data Mining: Principles, Design and Evolution, Master Thesis, Department of Mathematics and Computer Science, University of Quebec and Trois-Rivieres.

Sheybani, F. (2019). Predicting the Individuals' job satisfaction and determining the factors affecting it using the CHAID Decision Tree Data Mining Algorithm Case Study: the National Opinion Research Center of the United States. European Journal of Engineering Research and Science, 4(3), 6-9.

Talukdar, G. (2016). Human Resources Analytics: An Approach Towards Business Intelligence. International Journal of Computer Sciences and Engineering, 4(7), 125-129.

Wang, J., Chen, T. J. ve Chiu, S. H. (2005). Literature Review on Data Warehouse Development, IACIS PaciBic 2005 Conference Program, pp. 987-994.

Watson, H. J., Goodhue, D. L. ve Wixom, B. H. (2002). The benefits of data warehousing: why some organizations realize exceptional payoffs. Information \& Management, 39(6), pp. 491-502.

Yadav, S., Jain, A. ve Singh, D. (2018). Early Prediction of Employee Attrition using Data Mining Techniques, 2018 IEEE 8th International Advance Computing Conference (IACC), pp. 349-354. 